\title{
Editorial
}

\section{Atuação da cirurgia plástica nas feridas complexas}

\author{
Marcus Castro Ferreira
}

O desenvolvimento da civilização moderna foi acompanhado por aumento do tempo médio de vida mas, não necessariamente seguido por melhor qualidade de vida. $O$ inevitável aparecimento de problemas colaterais, principalmente relacionado a patologias crônicas,tem repercussões pessoais e econômicas, que não têm sido equacionadas de maneira adequada e integrada.

O tratamento das perdas de substância do revestimento cutâneo, chamadas genericamente de "feridas", é claramente uma dessas condições, tem sido de certo modo negligenciado pela classe médica, que lhe atribui caráter de menor sofisticação.

Parte significativa dessas feridas, aquelas mais recentemente denominadas "feridas complexas"1 acomete populações numerosas e o seu tratamento somente por métodos mais simples, como os curativos, não consegue resolver o problema (fechar a ferida em tempo mais curto), torna-se crônico, com custeio bastante elevado (aumento do numero e duração de internações hospitalares, maior uso de antibióticos e curativos) seja em pacientes públicos (SUS) ou de plano de saúde privados.

A resolução dessas feridas mais difíceis implica na introdução de procedimentos cirúrgicos e de novas tecnologias para reparação dos tecidos, em suma, é tratamento de maior complexidade que deve ser realizado pela área médica, em especial pela cirurgia plástica que tem contato com todos os tipos de feridas e dispõe de recursos técnicos para alcançar a reconstrução das perdas de substancia, principalmente com a experiência já conhecida e antiga no tratamento da queimadura, hoje conceituada como uma ferida complexa especial.

Em 2003, propusemos ao Instituto Central do Hospital das Clínicas atuação conjunta da Disciplina de Cirurgia Plástica com Grupo de Curativos (Estomaterapia) da Divisão de Enfermagem, visando melhor conhecimento e avaliação dos métodos para tratamento das feridas consideradas de maior morbidade, incluindo o cirúrgico, além de implementar a prevenção e reabilitação.

Consideramos como feridas complexas:

1. Feridas em MMII de pacientes diabéticos;

2. Ulceras por pressão;

3. Ulceras venosas;

4. Feridas conseqüentes a necroses extensas, pós-infecção;

5. Feridas associadas à radiação;

6. Feridas causadas por vasculites;

7. Feridas traumáticas agudas,perda extensa de partes moles; 
8. Feridas cirúrgicas complicadas;

9. Queimaduras profundas.

As três primeiras, ditas crônicas, despertaram maior interesse por haver, tradicionalmente, interação multidisciplinar em seu tratamento mas principalmente por constituirem, como foi dito, grave problema de saúde pública.

Atraiu também a atenção de alunos de Medicina da FMUSP que, em razão da pouca exposição ao tema dentro do curso curricular da Medicina,fundaram a Liga Acadêmica relacionada às feridas e queimaduras supervisionada pela Disciplina de Cirurgia Plástica. Sua atuação isolada foi intensa e interessante; fazendo atualmente parte da grande Liga de Cirurgia Plástica.

Como subsídio para sua parte teórica foi desenvolvida apostila do material didático apresentado em seus cursos. Esse material representa à atuação pioneira da Liga de Feridas, provavelmente a única manifestação sobre as feridas realizadas por acadêmicos e seus orientadores no Brasil.

A iniciativa da Diretoria da Revista de Medicina do Centro Acadêmico Oswaldo Cruz de editar número especial da Revista sobre a atuação da Cirurgia Plástica no tratamento das feridas complexas permitiunos retomar esse material que já tinhamos, com complexidade limitada para estudantes de medicina e áreas afins, ampliá-lo e agora torná-lo parte desta publicação tradicional, reconhecida por todos e símbolo de nossa Instituição.

\section{REFERÊNCIA}

1. Ferreira MC, Tuma Jr P, Carvalho VF, Kamamoto F. Complex wounds. Clinics. 2006;61:571-8.

\section{Marcus Castro Ferreira}

Professor Titular de Cirurgia Plástica da Faculdade de Medicina da Universidade de São Paulo. Chefe da Divisão de Cirurgia Plástica e Queimaduras, Hospital das Clínicas da Faculdade de Medicina da Universidade de São Paulo. 